\title{
Topics
}

\section{Epsilon Rocket Launcher and Future Solid Rocket Technologies}

\author{
By Yasuhiro Morita ${ }^{1)}$, Takayuki ImOTo ${ }^{1)}$, Shinichiro TOKUDOME ${ }^{1)}$, and Hirohito OHTSUKA ${ }^{2)}$ \\ 1) Japan Aerospace Exploration Agency (JAXA), Sagamihara/Tsukuba, Japan \\ ${ }^{2)}$ IHI Aerospace Co.,Ltd.(IA), Tomioka, Japan
}

(Received June 28th, 2011)

The Epsilon rocket, formerly called Advanced Solid Rocket (ASR) launcher, proceeded to the full development phase in August 2010 and its launch site was officially declared to be the Uchinoura Space Center (USC), the home of Japanese solid propellant rocket. The primary purpose of Epsilon is to provide small satellites with a responsive launch that means a low cost, user-friendly and ultimately efficient launch system. The slogan is "Small, Cheap, Fast and Reliable". This outcome is also a result of the excellent endeavors of those who devoted themselves to the next generation solid propellant rocket. However, this is not the final destination. Now that the development was approved, the most important is what the next step should be beyond Epsilon. This paper deals with the significance of the development of Epsilon launch vehicle and how it contributes to the possible evolution of future space transportation systems.

Key Words: Solid Propulsion, Mobile Launch Control

\section{Introduction}

The development of Epsilon rocket, Japan's next generation solid rocket launcher, was formally approved by Space Activities Commission (SAC) of Japan in August 2010, four years after the $\mathrm{M}-\mathrm{V}$ rocket launched its last payload. The Epsilon rocket, formerly called Advanced Solid Rocket (ASR) launcher, is the successor to the $\mathrm{M}-\mathrm{V}$ launch vehicle. The SAC recognized the advantages of combined power of small satellites and the autonomous launch system. SAC further declared that the Epsilon's first flight will be conducted in 2013 to carry the planetary telescope satellite SPRINT-A. The purpose of the Epsilon rocket is to provide small satellites with a responsive launcher, which means in this study we focus on a low cost, user-friendly and ultimately efficient launch system. ${ }^{1-3}$

From the point of view of the space transportation research, it is most important to develop the next generation technologies for Epsilon such as the autonomous check-out system and the mobile launch control, which will make the Epsilon rocket far ahead of the world. Such innovative technologies will make the ground facilities and operations as compact as possible and will be applied to the H2A rocket as well and will eventually become the world standard after the development of Epsilon. In addition, the simplification of such launch control should be the technology that is indispensable to future reusable rocket systems. In this way, the concept of Epsilon rocket is beyond the scope of mere solid-propellant rockets. Rather Epsilon rocket aims at achieving the innovative transportation technologies that can be equally applicable to liquid fuel rockets as well as future space transportation systems. The launch site of Epsilon was officially declared to be the Uchinoura Space Center (USC), the home of Japanese solid propellant rockets (Fig.1). Originally, the Uchinoura Space Center was known for its unique compactness, and it will be much more improved with a mobile launch control system. With this impressive combination of a simple structure solid-fuel rocket and a compact launch site, the Epsilon will undertake missions to reduce the threshold of access to space for everyone.

Now that the scope of the development has been defined and the full-scale development has been approved, the most important is what the next step should be beyond Epsilon. JAXA proposes the post Epsilon development to launch the low cost version Epsilon in 2017 based on the study on the radically low cost technologies, primarily in avionics and

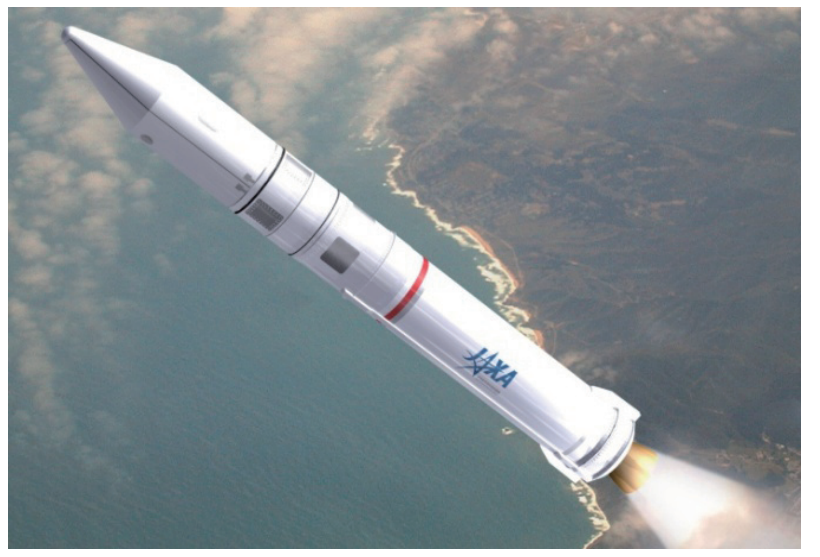

Fig. 1. Artistic view of the flight of Epsilon rocket, which is expected to be launched in 2013. 


\begin{tabular}{|c|c|c|c|c|c|c|c|c|}
\hline 2009 & 2010 & 2011 & 2012 & 2013 & 2014 & 2015 & 2016 & 2017 \\
\hline \multicolumn{2}{|c|}{ SAC approved $\Delta$} & & \multicolumn{2}{|c|}{ Epsilon launch $\Delta$} & & & & \\
\hline $\begin{array}{l}\text { conceptual } \\
\text { study }\end{array}$ & $\begin{array}{l}\text { preliminary } \\
\text { design }\end{array}$ & detailed design & \multicolumn{2}{|c|}{ liaison engineering } & & & & \\
\hline & & & & & & & \multirow{2}{*}{\multicolumn{2}{|c|}{ Low cost Epsilon $\Delta$}} \\
\hline & & & & & & & & \\
\hline & \multicolumn{3}{|c|}{ Study on low cost technologies } & \multicolumn{3}{|c|}{ Design \& Development } & \multicolumn{2}{|c|}{ Manufacture \& test } \\
\hline & & & & & & & & \\
\hline
\end{tabular}

Fig. 2. Two step development plan of the Epsilon rocket.

structural systems, which are planned to be conducted in parallel with Epsilon development (Fig. 2). The idea and the scope of the study were also approved by SAC and the targeted launch cost is set at below US\$30 million to be competitive in the world market.

In addition to the study that was conducted for the post Epsilon development, there must still be more effort to evolve the Epsilon rocket and enhance the space transportation technologies in the larger scale. Once the mobile launch control is realized in the Epsilon development using an intelligent check-out system, it will be considered natural that the intelligence of the rocket should be further enhanced by making even the flight safety control autonomous, which will eliminate those expensive tracking facilities, making the tracking control system highly compact and mobile. Our attention should then be directed toward a revolution of manufacture that will convert the current large-scale and inefficient manufacturing processes to a much smaller scale and higher utilization frequency. This is the dimension that we hardly considered seriously until now, but it cannot be avoided to achieve lower-cost and more frequent space activities. This paper deals with the details of the development of Epsilon and reveals its possible evolution.

\section{Design Concept of The Epsilon Rocket}

The purpose of the Epsilon rocket is to provide small satellites with responsive launch, which means a low cost and ultimately efficient launch system. Throughout 50 years history of Japan's solid rockets, the research was conducted only to increase the rocket performance. Now, for the first time ever in history, the rocket requires an optimization of the entire launch system, including the efficient launch operations and the compact ground facilities. This attempt will contribute equally to the possible evolution of the liquid rockets as well as future space transportation systems.

\subsection{Development plan of Epsilon rocket}

JAXA announced the two-step development of Epsilon rocket: as the first step of development, the target is to achieve the next generation technologies such as the rocket intelligence and the mobile launch control while minimizing the cost and period needed for development. The first launch will occur in 2013 and the launch cost will be US\$38 million (US\$ $\approx ¥ 100$ ). In the second step, the research and the development will be conducted to realize radically low cost technologies, mainly in the avionics and structural systems, that are planned to be conducted in parallel with the first step
Epsilon development. The second generation Epsilon is planned to be launched in 2017. The idea and the scope of the study were also approved by SAC and the targeted launch cost is set at below US\$30 million to be competitive in the world market. This chapter describes the first step Epsilon in details and the research on low cost technologies in the second step of development is referred to in the next section together with other possible next generation technologies.

\subsection{Concept and configuration of Epsilon rocket}

As an advanced version of the $\mathrm{M}-\mathrm{V}$ rocket, the Epsilon rocket launch vehicle has three special aspects in development: the optimization of the rocket configuration, the reform of the launch system, and the enhancement of user friendliness. The first topic is related to the design of the rocket system. The M-V rocket was optimized virtually only in launch performance to tackle with the relatively small development budget in spite of strong demand for large launch capacity. In sharp contrast, the Epsilon rocket is optimized in launch performance as well as operation cost.

Generally speaking, it is not always easy because performance and cost are naturally two competing indexes. The key to success is the idea of sensitivity to launch performance. It should be recognized that the first stage motor is relatively expensive mainly due to its relatively large size while its sensitivity to the entire rocket's launch capacity is not so high. Thus it is reasonable to utilize the low cost but medium-performance SRB-A, a side booster of the H-2A launch vehicle, as the first stage rocket. On the other hand, the second and third stage motors have significantly high sensitivity to the launch performance though they are inexpensive due to their relatively small scales. Therefore, at those stages, the high-performance third and kicking stage motors of the $\mathrm{M}-\mathrm{V}$ vehicle are utilized. In addition, their performance is planned to be further enhanced by making the motor case lighter. As a result, the performance of the second and the third stage motors of the Epsilon can be expected to exceed that of the M-V launcher. Those extremely high-performance upper-stage motors will produce as high payload ratio of the entire launch vehicle as the $\mathrm{M}-\mathrm{V}$ rocket despite utilizing a sub-optimal first stage motor to reduce the cost (Fig. 3).

As a result, the configuration of the advanced solid rocket is taken to be a three-staged launch vehicle having an optional upper stage engine for better orbit insertion precision and maneuverability, which may be propelled by conventional hydrazine engine. The entire lift-off mass is approximately 90 ton with the total length and maximum diameter to be $24 \mathrm{~m}$ and $2.5 \mathrm{~m}$, respectively. Its launch capacity is two thirds of that of the M-V rocket: 1.2 ton into a low earth orbit (LEO) and 0.45 ton into a sun synchronous transfer orbit (SSTO). Its cost is projected to be only a half of the former M-V Launch Vehicle, a significant improvement in cost and performance. The first launch is scheduled for 2013 (Table 1). 


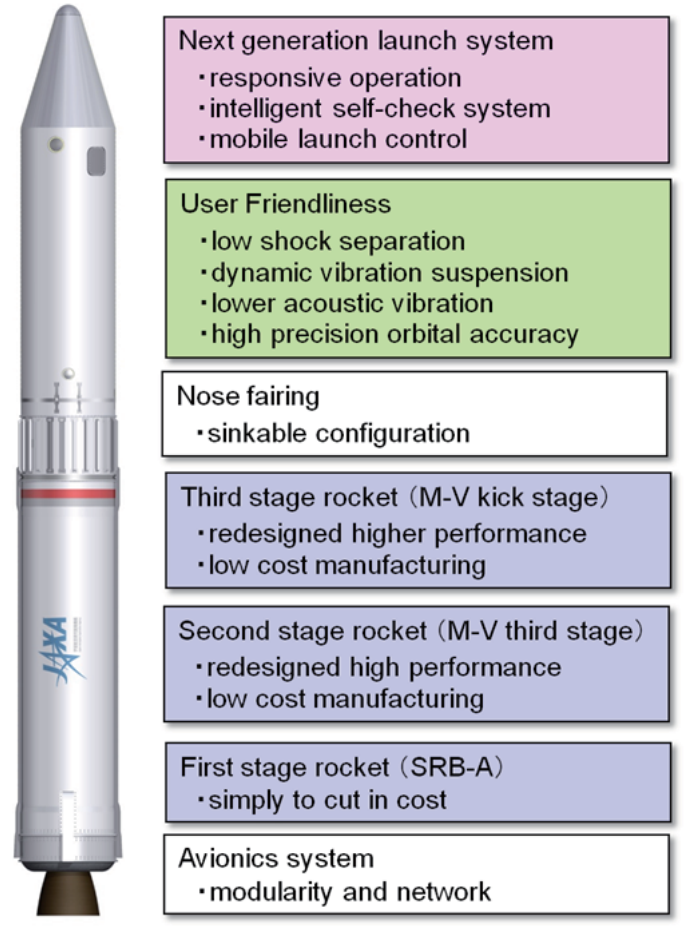

Fig. 3. Innovative design concept and the configuration of the Epsilon rocket, which is loaded with the next generation technologies.

\subsection{Intelligent launch control}

The other special feature of the Epsilon development is an evolution of the launch system, which is intended to dramatically increase availability of the rocket and to reform the current launch system into responsive launch by improving the operation performance to the highest standard of the next-generation. The key to success is an innovation of the onboard avionics system. ${ }^{4-5}$ It is designed to be connected with the ground support facilities by a high-speed network. In addition, it is designed to be highly intelligent so that the vehicle performs checks onboard and autonomously, which can reduce the associated time and labor required for operations on the ground and make the ground facilities absolutely compact ${ }^{5}$.

There are two representative applications of intelligent check-out. One is the check-out of the onboard ignition system that is derived by extending the idea of self-check in air-bag ignition control for automobiles. The trial manufacture examination has already finished for Epsilon rocket and it is assured that the physical and safety properties will be well within the scope of expectation. The other example is a diagnosis of the driving current pattern of the mobile nozzle which can be considered more intelligent because it is aimed at taking over the role of expert engineers. In this study, an artificial intelligence technology or quality engineering, the Mahalanobis-Taguchi method (MT method), was utilized. This technique is already used for an autonomous diagnosis of the electrocardiogram. The technique uses the Mahalanobis distance for diagnosis, which is equal to the distance from the correlation surface that the normal data would have. This will
Table 1. Representative specifications of the Epsilon rocket.

\begin{tabular}{|c|c|}
\hline Items & Specifications \\
\hline Configuration & $\begin{array}{c}\text { 3-stage } \\
\text { (PBS optional) }\end{array}$ \\
\hline Length/ Diameter & $24 \mathrm{~m} / 2.5 \mathrm{~m}$ \\
\hline Lift-off mass & 92 ton \\
\hline Capacity & $\begin{array}{l}\text { LEO: } 1.2 \text { ton } \\
\text { SSO: } 450 \mathrm{~kg}\end{array}$ \\
\hline Operational cost & $38 \mathrm{M} \$$ \\
\hline $\begin{array}{l}\text { Innovative } \\
\text { Technologies }\end{array}$ & $\begin{array}{l}\text { Autonomous checkout } \\
\text { Mobile launch control }\end{array}$ \\
\hline Development cost & $209 \mathrm{M} \$$ \\
\hline Launch year & 2013 \\
\hline First Payload & SPRINT-A \\
\hline \multicolumn{2}{|c|}{$\begin{array}{l}\text { PBS: Post Boost Stage US } \$=¥ 100 \\
\text { LEO: Low earth Orbit } \\
\text { SSO: Sun Synchronous Orbit }\end{array}$} \\
\hline
\end{tabular}

reduce the possibility of wrong diagnosis as compared to judgement based on mere thresholds. The prototype models of such intelligence as autonomous diagnosis and check-out were already established so that the effectiveness of the approach was verified (Fig. 4).

Owing to this endeavor, the check-out of the onboard ignition system will be performed remotely, safely, and instantaneously. Currently, it takes four days for the check-out because it requires the highest level of safety. Ultimately, through the network, it will be possible to check and control rockets anytime and anywhere in the world simply by using a single laptop computer ${ }^{6}$. This is called a mobile launch control (Fig. 5). Consequently, the time needed for the ground operation is dramatically reduced as compared to other representative small rockets in the world in time required for the fundamental ground operations (Table 2). As clearly indicated, the operation efficiency of the Epsilon launcher can be considered the best in the world. Such an innovative concept of the Epsilon will open doors for future launch systems.

\subsection{User friendly interface}

The level of user friendliness of the Epsilon launcher is planned to be enhanced to exceed the already high performance $\mathrm{M}-\mathrm{V}$ launch vehicle. For more versatile orbital maneuverability and more accurate orbital injection, an optional tiny post-boost stage (PBS) can be installed atop the third stage rocket motor, which utilizes small hydrazine engines, virtually identical to the attitude control engines of the M-V (Table 3). By using this option, a wide variety of orbits, such as solar synchronous orbit and even a planetary trajectory, that small satellites require can easily be reached. In addition, the accuracy of trajectory can be increased to as high as that of liquid propellant rockets; hence, it will be better than that of the $\mathrm{M}-\mathrm{V}$ rocket $^{7-8}$. 


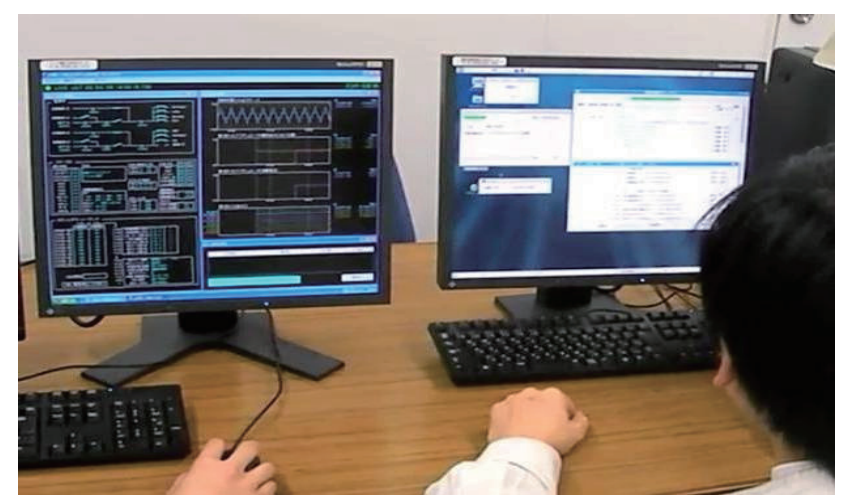

Fig. 4. Picture taken at the scene of demonstration tests of the autonomous check-out system for the mobile launch control.

Another service that small satellites most welcome will be the reduction of mechanical environment. In particular, the acoustic environment is planned to be lowered by introducing a special ground facility and utilizing a refined method of numerical analysis ${ }^{9}$. Note that the acoustic environment of solid propellant rockets is relatively severe as compared to that of liquid propellant vehicles due to its higher thrust at ignition.

\section{Next Step Beyond Epsilon}

The development of Epsilon aims at reforming the current rocket launch system to one of the much more efficient scale by using the innovative intelligent launch control. This idea is aligned with a long term goal to realize much more compact and much more low cost launch system beyond Epsilon and pave the way to the future space transportation systems. ${ }^{10-14}$ In this section, post-Epsilon key technologies will be discussed.

\subsection{Radically low cost technologies}

As already indicated, JAXA plans the post-Epsilon development to realize the radically low cost technologies, mainly in avionics and structural systems, that will be conducted in parallel with the Epsilon development. The second generation Epsilon, loaded with such low cost technologies, is scheduled to be launched as early as 2017 . The idea and the scope of the study were also approved by SAC. One of the keys to success of the post Epsilon development is the innovative architecture of the onboard avionics systems. Although the avionics systems of the H2A

Table 2. Efficient operations of the Epsilon rocket as compared in time required for the fundamental ground operations.

\begin{tabular}{|l|c|c|c|}
\hline \multicolumn{1}{|c|}{ Items } & Epsilon & $\begin{array}{c}\text { Overseas } \\
\text { rockets }\end{array}$ & $\mathrm{M}-\mathrm{V}$ \\
\hline $\begin{array}{l}\text { Days needed from first } \\
\text { stage on pad to launch }\end{array}$ & 6 & $\begin{array}{c}\text { Minotaur-1 } \\
25 \\
\text { Falcon-1 } \\
10\end{array}$ & 47 \\
\hline $\begin{array}{l}\text { Hours for last access } \\
\text { to launch }\end{array}$ & 3 & $\mathrm{~N} / \mathrm{A}$ & 6 \\
\hline Cost in launch site & $<2 \mathrm{M} \$$ & $\mathrm{~N} / \mathrm{A}$ & $10 \mathrm{M} \$$ \\
\hline
\end{tabular}

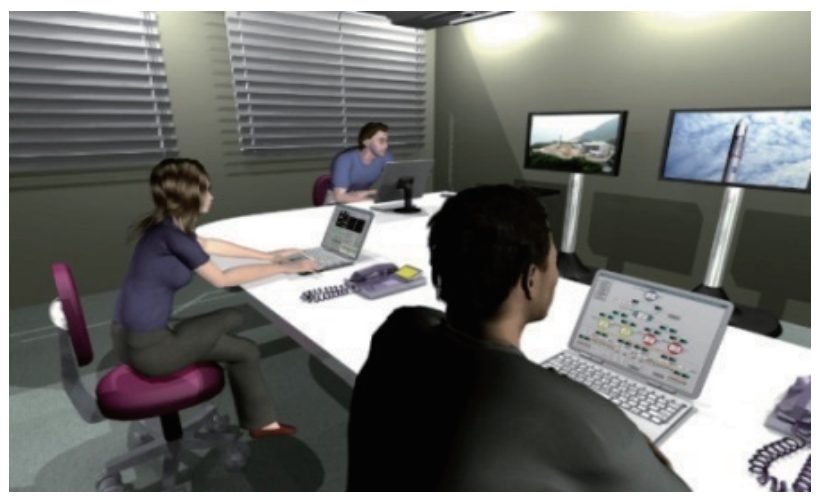

Fig. 5. Artistic image of the mobile launch control.

rocket are used for the first generation Epsilon in order to minimize the development cost, much more inexpensive avionics should be developed for the second generation Epsilon. The idea is to utilize commercial parts: the latest generation of those components are smaller, lighter and cheaper. Note, the same trend is already observed in some satellite development. Of course, special consideration is necessary for rocket applications with respect to parts reliability because of the limited redundancy of rocket guidance and control subsystem

Another idea to success of the post Epsilon development is to convert the metallic rocket structures to ones made of CFRP. Moreover, the CFRP structures will be molded into almost the final shape: the near-net shape method. By this effort, the assembly process can be minimized. This strategy already brought success to the aviation industries. They could cut cost of structures by $50 \%$. The same application to the space industries is one of the most promising fields and is already defined as the research target for post Epsilon.

\subsection{Mobile tracking control}

In addition to the above effort, the intelligence of rockets will be further enhanced by making the flight safety control autonomous, which means the rockets are designed to detect their own trajectories and conduct safety operations by

Table 3. Representative specifications of PBS. Note, the detail is under study.

\begin{tabular}{|l|c|}
\hline Properties & Designed \\
\hline Total Mass & $\begin{array}{c}<280 \mathrm{~kg} \text { including } \\
\text { onboard avionics and } \\
\text { guidance \& control. }\end{array}$ \\
\hline Engine & $\begin{array}{c}\text { Hydrazine } \\
\text { A class of M-V side jet } \\
\text { (mono propellant) }\end{array}$ \\
\hline Pressure System & N2 blow down or regulated \\
\hline Container & Cartridge \\
\hline Thrust & $\begin{array}{c}\text { min. } 50 \mathrm{~N}(25 \mathrm{NX} 2) \\
\text { max. } 200 \mathrm{~N}\end{array}$ \\
\hline Isp & \begin{tabular}{c}
$>215 \mathrm{~s}$ \\
\hline Fuel
\end{tabular} \\
\hline
\end{tabular}




\begin{tabular}{|l|}
\hline Semi-autonomous \\
Tracking radar eliminated \\
Command antenna required \\
$<$ Onboard $>$ \\
$\cdot$ GPSR/IMU $\times 2$ \\
$\cdot$ Telemetry downlink $\times 2$ \\
. Command decoder $\times 2$ \\
$<$ Ground $>$ \\
$\cdot$ Telemetry Receiver $\times 2$ \\
$\cdot$ Command $\times 2$ \\
\hline
\end{tabular}

\begin{tabular}{|l|}
\hline Fully autonomous \\
Tracking radar eliminated \\
Command antenna eliminated \\
$<$ Onboard $>$ \\
$\cdot$ GPSR/IMU $\times 2$ \\
$\cdot$ Telemetry downlink $\times 2$ \\
- Onboard CPU $\times 2$ \\
$<$ Ground $>$ \\
$\cdot$ Telemetry Receiver $\times 2$ \\
\hline
\end{tabular}

Fig. 6. Idea of a step-by-step evolution of the autonomous flight safety control.

themselves if necessary. This will eliminate the expensive tracking radars and their facilities, thus making the entire launch complex as simple as only a mobile telemetry station, an extreme mobility of the launch system. Such a high level of autonomous character will lead to a diversity of launch systems involving air launch because it doesn't need a gigantic launch complex any more. Of course, a strong opposing opinion is seen in such an innovative idea; however, it cannot be forgotten that there was also intense resistance for the autonomous rocket check-out at first and we finally overcame it. It is absolutely one of the challenges that should be realized before long. The mobile tracking control can be realized in a more moderate way. For example, the telemetry data of onboard GPS or inertial sensor will substitute the tracking radar as well, though in a limited fashion (Fig. 6).

\subsection{Advanced solid rocket propellant}

Finally, for the first time ever in history again, our attention is directed toward a revolution of manufacture, which is aimed at more compact manufacture facilities and more efficient production process. Yes, one of the key factors pushing up the price of the rockets is the inefficient large scale manufacturing process. The current process of the solid rocket fuel, for example, consists of: mixing the binder (poly-butadiene), the oxidizer (ammonium parchlorate) and the aluminum powder with a mixer; then molding them into the motor case, finally it's heated so that the elastomer becomes stiffened. The problem stays in this final approach, the thermal curing, which is a one-way no-return reaction. Thus the entire process, the mixing and the molding, cannot be stopped once started. Therefore, the manufacture facilities, even the mixer, become gigantic although their utilization rate is very low: that is an absolutely inefficient manufacture process.

This is why the novel propellant is now under study: it is known as Low melting temperature Thermoplastic Propellant (LTP) ${ }^{15-18}$ This one has a reverse nature: the two-way thermal elasticity, that is, it remains solid at room temperature and melts when heated, just like a chocolate bar. We can repeat this process as many times as we want: owing to this nature, the entire manufacturing process can be intermitted now and the mixing and the molding can be conducted independently and separately both in time and space. From now on, the chocolate bar-type propellant can be mixed with a laboratory-scale small mixer in a small facility, can be

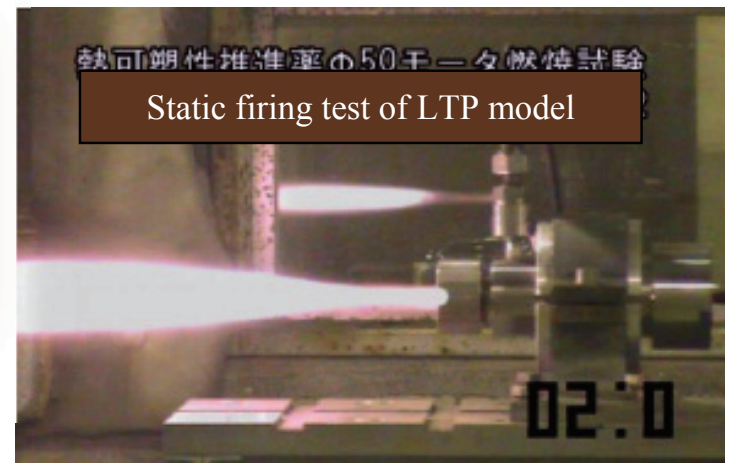

Fig. 7. Picture taken by a high speed camera at the static firing test of an LTP model, which has enough burning and mechanical properties.

produced continuously day and night, and finally can be stored in a stock house, absolutely like a chocolate bar, thus raising the use rate of the mixer almost $100 \%$. The loading of the fuel can be easily done at a launch site by simply melting propellant bars and molding them into the motor case at an automatic mass-production style. In this way, the manufacturing process can be converted to one of a much smaller scale and higher utilization frequency, thus resulting in a much more efficient manufacturing process.

A static firing test, though in a limited scale, was already performed (Fig. 7), in which the thermo-plastic binder is chosen to be a butadien elastomer having additional plasticizer and bonding agent for characteristic improvement. Adding AP and Aluminum powder to the binder established a practical model of LTP that has enough burning and mechanical properties (Table 4). Although the static firing test was conducted using a relatively small test motor having only 50 $\mathrm{mm}$ in diameter, its manufacture process was actually a simulation of that of full scale rocket motors. As the first step of the manufacture, small blocks of propellant bars were hand-made and put inside the motor case. Then they were heated at $90^{\circ} \mathrm{C}$ under the vacuum environment so that the propellant was casted in the motor case by its thermal fluidity. Finally, they became stiffened after being kept at a room temperature. This is how we successfully demonstrated the manufacture process of LTP.

Table 4. Representative characteristics of the current LTP practical model as compared with the upper stage propellant of Epsilon.

\begin{tabular}{|c|c|c|}
\hline index & LTP model & BP-204J \\
\hline Theoretical Isp (s) & 256 & 260 \\
\hline Buming rate (mm/s) & 5.9 & 9.2 \\
\hline Pressure index & 0.37 & 0.38 \\
\hline $\begin{array}{c}\text { Mechanical \& } \\
\text { Manufacturing } \\
\text { Properties }\end{array}$ & good & good \\
\hline
\end{tabular}

BP-204J: Epsilon's upper stage propellant

LTP model: TPE binderIAPIAI $=18 / 66 / 16$ 


\section{Conclusion}

This paper details the development of the Epsilon rocket, Japan's next generation solid rocket launcher, which was formally approved by the Space Activities Commission (SAC) in August 2010. The first flight is planned to be in 2013. The primary purpose of Epsilon is to provide small satellites with a responsive launch that means a low cost, user-friendly and ultimately efficient launch system. The slogan is "Small, Cheap, Fast and Reliable". To realize it, the Epsilon rocket is loaded with the various next generation technologies such as the intelligent check-out system and the mobile launch control. Such innovative technologies will make the ground facilities and operations as compact as possible and will eventually become the world standard after the development of Epsilon. Furthermore, the launch site of Epsilon was recently officially declared to be the Uchinoura Space Center (USC), the home of Japanese solid propellant rocket. Originally, the Uchinoura Space Center was known for its unique compactness, and it will be significantly improved with a mobile launch control system. With this impressive combination of a simple-structure solid-fuel rocket and a compact launch site, the Epsilon will undertake missions to reduce the threshold of access to space for everyone. During the past two years, the prototype models of such advanced technologies were already established and the effectiveness of the approach was verified for practical use. Now that the Epsilon development shows the steady progress, what the post Epsilon development should be will become much important. One of the key technologies is to make the tracking control ultimately compact and mobile by enhancing the intelligence of the rocket. The attention should also be directed toward a revolution of the manufacture, which is aimed at more compact manufacture facilities and more efficient manufacture process. The innovative design concepts and the associated key technologies of both Epsilon and post-Epsilon will contribute to the possible evolution of future space transportation systems.

\section{References}

1) Morita, Y.: Responsive Launch System for Small Satellites, $5^{\text {th }}$ Symposium on Space Sciences, Institute of Space and Astronautical Science (ISAS), JAXA (2006).

2) Morita, Y.: Research on Solid Propellant Rockets, $6^{\text {th }}$ Symposium on Space Sciences, Institute of Space and Astronautical Science (ISAS), JAXA (2008).

3) Morita, Y., Imoto, T. and Ohtsuka, H.: Research on an Advanced Solid Rocket Launcher in Japan, $26^{\text {th }}$ ISTS, paper No. 2008-g-02 (2008) / also published by the Japanese Rocket Society, Journal of Space Technology and Science, 24, No. 1, (2008), pp. 1-6.

4) Kawase, M., Tamura, M., Sunami, K., Izumi, T. and Morita, Y.: The Avionics System Design Concept for the Advanced Solid Rocket, $26^{\text {th }}$ ISTS, paper No. 2008-g-03/ also published by the Japanese Rocket Society, Journal of Space Technology and Science, 24, No. 1,(2008), pp. 13-16.

5) Kato, K., Imoto, T., Miho, K. and Arakawa, S.: The Autonomous Check-out System Concept Design for the Advanced Solid Rocket, $26^{\text {th }}$ ISTS, paper No. 2008-a-31.

6) Miho, K.: A Compact and Innovative Launch Operation Concept of the Advanced Solid Rocket, $26^{\text {th }}$ ISTS, paper No. 2008-g-04.

7) Mayumi, A., Ohtsuka, H., Yagi, K., Morita, Y. and Habu, H.: Advanced Solid Rocket for Various Small-sat Missions, $26^{\text {th }}$ ISTS, paper No. 2008-g-01/ also published by the Japanese Rocket Society, Journal of Space Technology and Science, 24, No. 1, (2008), pp. 7-12.

8) Tanaka, K., Otsuka, H., Saito, K., Tamura, T., Ishii, N., Maeda, Y. and Morita, Y.: PBS(Post Boost Stage) Design of the Advanced Solid Rocket, $27^{\text {th }}$ ISTS, paper No. 2009-a-19.

9) Tsutsumi,'S., Fukuda, K., Takaki, R., Shima, E., Fujii, F. and Ui, K.: Numerical Analysis of Acoustic Environment for Designing $\mathrm{L}^{\text {au }}$ nch-Pad of Advanced Solid Rocket, $26^{\text {th }}$ ISTS, paper No. 2008-g-05.

10) Morita, Y., Hori, K., Koreki, T. and Akiba, R.: Research on Next Generation Solid Propellant Rockets, Symposium on Space Transportation Systems, Institute of Space and Astronautical Science (ISAS), JAXA (2008)

11) Morita, Y., Hori, K., Koreki, T. and Akiba, R.: Research on Next Generation Solid Rocket Launchers, Symposium on Space Transportation Systems, Institute of Space and Astronautical Science (ISAS), JAXA (2009).

12) Morita, Y., Imoto, T., Habu. H., Otsuka, H., Hori, K., Koreki, T., Fukuchi, A., Uekusa, Y. and Akiba, R.: Advanced Solid Rocket launcher and its Evolution, $27^{\text {th }}$ ISTS, paper No. 2009-g-18 (2009).

13) Morita, Y., Imoto, T., Habu, H. and Ohtsuka, H.: "Japan's Next Generation Solid Rocket Launcher," 60th Congress of the International Astronautical Federation (IAC), Daejeon, Republic of Korea, 2009, Paper No. IAC-09.D2.1.9.

14) Morita, Y. Hori, K. Imoto, T. Ohtsuka, H. Fukuchi, A. and Akiba, R.:"Advanced Solid Rocket Launcher and beyond," 12th International Space Conference of Pacific Basin Societies (ISCOPS), Montreal, Canada, July 2010/ also to be published by the American Astronautical Society, Advances in the Astronautical Sciences.

15) Hori, K., Kasahara, T., Hasegawa, T., Katoh, K., Miyazaki, S., Maruizumi, H., Morita, Y. and Akiba, R.: A Study of New Composite Thermoplastic Propellant, $26^{\text {th }}$ ISTS, paper No. 2008-a-27.

16) Fukuchi, A., Matsuura, S., Miyazaki, S., Maruizumi, H., Hori, K., Morita, Y. and Akiba, R.: Experimental Research on Low Temperature Melting Composite Propellant for Next Generation Solid Rocket, $27^{\text {th }}$ ISTS, paper No. 2009-a-17.

17) Morita, Y.: "Advanced Solid Rocket Propellant for Cost Effective Launchers," IAA 50th Anniversary Celebration Symposium, Nagoya, Japan, August 2010.

18) Morita, Y., Imoto, T. and Ohtsuka, H.: "Development of Japan's Next Generation Solid Rocket Launcher- the Epsilon Rocket," 61st Congress of the International Astronautical Federation (IAC), Prague, Czech Republic, 2010, Paper No. IAC-10.D2.1.7. 